\title{
Study of the properties of metal powder received by plasma
}

\author{
Azat Gabdrakhmanov ${ }^{1, *}$, Lenar Shafigullin ${ }^{1}$, Tansylu Gabdrakhmanova ${ }^{1}$, and Azat \\ Galiakbarov $^{1}$ \\ ${ }^{1}$ Kazan Federal University, Sjujumbike street 10a, Naberezhnye Chelny, 420008 Republic Tatarstan
}

\begin{abstract}
In this work, a new method for producing metal and ceramic powders by plasma spraying of rod blanks is proposed. A distinctive feature of this method is the use of a direct-acting plasmatron, where a bar-stock acts as one of the electrodes, and the cooling of the molten particles occurs place with a water screen. The water screen is not only in the lower part of the installation, but also it flows evenly from the walls, which gives a more efficient cooling of all molten particles, forming a regular spherical shape, and plasma flow. Water constantly circulates in a closed circuit, the heat is removed in a heat exchanger. Studies of powders were performed on scanning electron microscope "VEGA 3 LMH" produced by the company TESCAN, the Czech Republic, with the help of x-ray energy dispersive microanalysis AZtecEnergy Advanced busatti detector X-max 20 Standart, production company Oxford Instruments. The microhardness of the particles was measured according to GOST R ISO 6507-1-2007 on a MicroMet 5104 microhardness meter, with a load of 100 gs.
\end{abstract}

\section{Introduction}

Additive technologies allow for simplifying the production of products of complex in shape and non-technological products at the present level of development using universal equipment. Additive technologies are recognized by the leading countries in the world as the main advanced industrial technologies. The Russian Federation has significantly lagged behind in the development of additive technologies from the United States, Japan, Europe, China and Israel. In the medium term, Russia risks becoming dependent on advanced industrial technologies of Western countries and losing its technological sovereignty. In this regard, the development of this technology in our country and the production of raw materials for additive equipment (powders) is today an urgent task.

The production method of metal powder affects the quality and cost. Physico-chemical and mechanical methods for the preparation of metal powders are widely used in industry. Metal powders differ in chemical, physical and technical parameters. The main verified

* Corresponding author: veyron000@mail.ru 
parameters are: particle morphology, specific surface area of particles, chemical and phase composition of particles [13, 14]. Widening the field of application, increase of the nomenclature and requirements to quality of production demanded introduction of new requirements to production of powders at the expense of management of technological parameters of production $[15,16]$. Further chemical, thermal and mechanical processes are used to achieve the required quality and cost parameters in the manufacture of powders.

It is possible to use a highly concentrated heat source, in particular a plasma jet to solve the problem of obtaining metal powders of various nomenclatures with the required properties, A distinctive technological feature of the use of a plasma jet is a higher concentration of the energy of the heating source and its forceful effect on the heating zones. The influence of plasma characteristics on the properties of sprayed materials is obvious [4].

This work is devoted to the development of an installation for the production of metal powders with a given shape and particle size, using a plasma-arc spraying technology with a water screen, used in additive technologies, characterized by a modular structure of the sprayed chamber to facilitate its maintenance and repair, the presence of a cooling chamber with a water screen for more efficient cooling of sprayed metal particles.

\section{Experimental studies}

In this work, a new method for producing metal and ceramic powders by plasma spraying of rod blanks is proposed. A distinctive feature of this method is the use of a direct-acting plasmatron, where a bar-stock acts as one of the electrodes, and the cooling of the molten particles occurs place with a water screen. The water screen is not only in the lower part of the installation, but also it flows evenly from the walls, which gives a more efficient cooling of all molten particles, forming a regular spherical shape, and plasma flow. Water constantly circulates in a closed circuit, the heat is removed in a heat exchanger.

The input raw material in the proposed installation is a wire of various materials with a diameter of $0.8-2 \mathrm{~mm}$. Studies of powders obtained from welding wire ER70S-6 are provided in this work. Welding wire ER70S-6 - one of the most common popular options due to the fact that it has the optimal component composition. It is used for a wide variety of types of welding and welding. The composition of products in accordance with regulatory documentation should include: $\mathrm{C}=0.05-0.11 \%$; $\mathrm{Mn}=1.8-2.1 \%$; $\mathrm{Si}=0.70-$ 0.95\%; $<<0.025 \%$; P <0.03\%; $\mathrm{Cu}<0.25 \%$.

The total copper content for wire with a coating of not more than $0.3 \%$ (including copper coating, with a thickness of at least 0.1 microns).

The composition can also include no more than $0.25 \%$ nickel and no more than $0.2 \%$ chromium.

Figure 1 shows a sample of powder obtained by plasma spraying: 

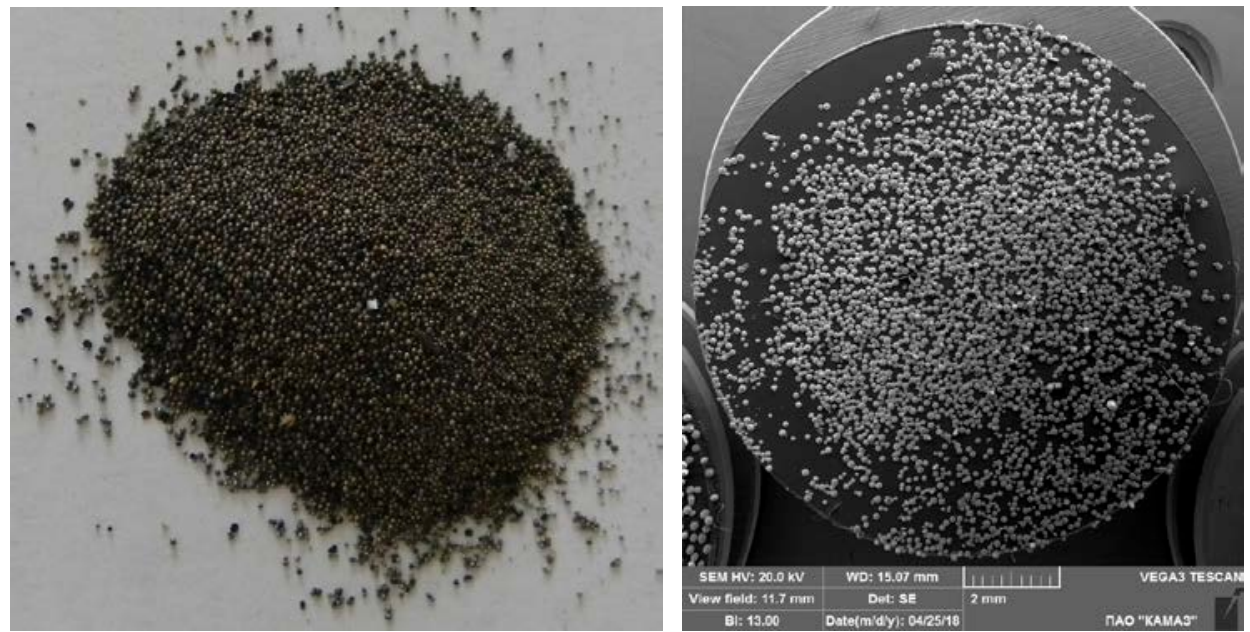

Fig. 1. Sample powder obtained by plasma spraying

Studies of powders were performed on scanning electron microscope "VEGA 3 LMH" produced by the company TESCAN, the Czech Republic, with the help of x-ray energy dispersive microanalysis AZtecEnergy Advanced busatti detector X-max 20 Standart, production company Oxford Instruments. The study of powders was carried out from the surface and the cross section of the particles. The results of these studies are shown in figure 2.

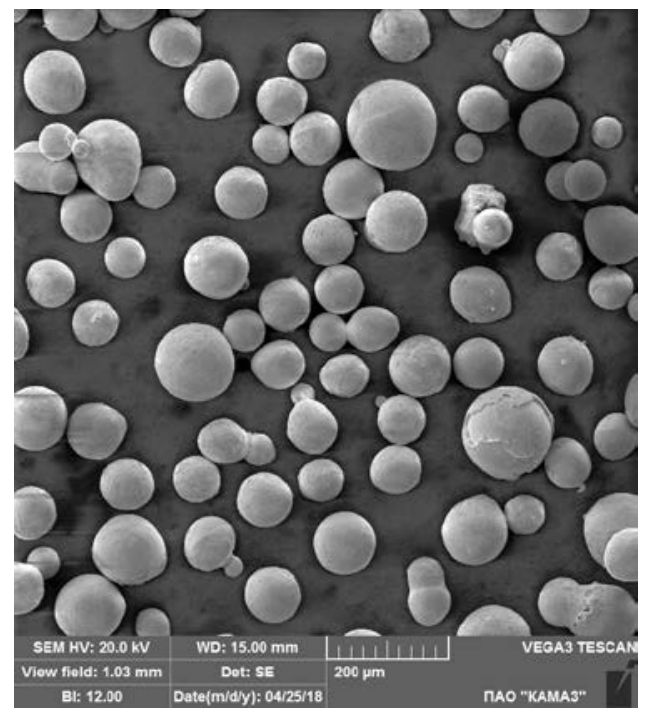

$\times 200$

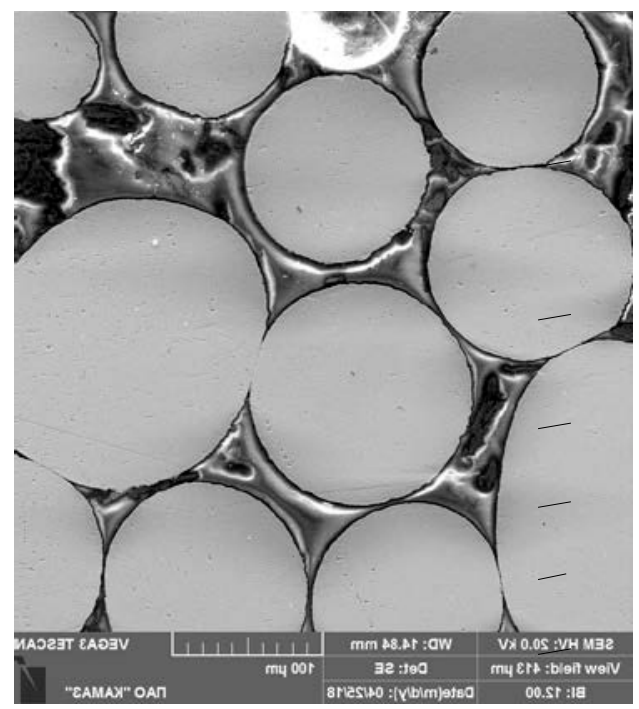

$\times 500$

Fig. 2. Powder sample obtained by plasma spray

The microstructure studies of the powders were carried out in the cross section of the particles. The microstructure of the particles is identical and is a low carbon martensite, in accordance with figure 3 . 


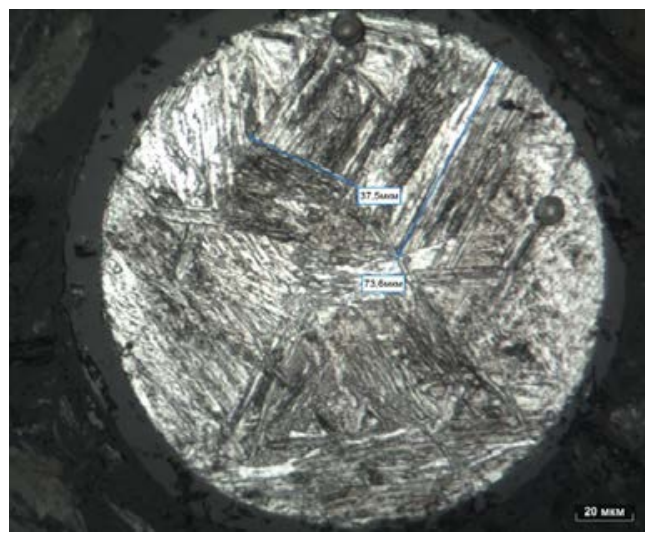

$\times 500$

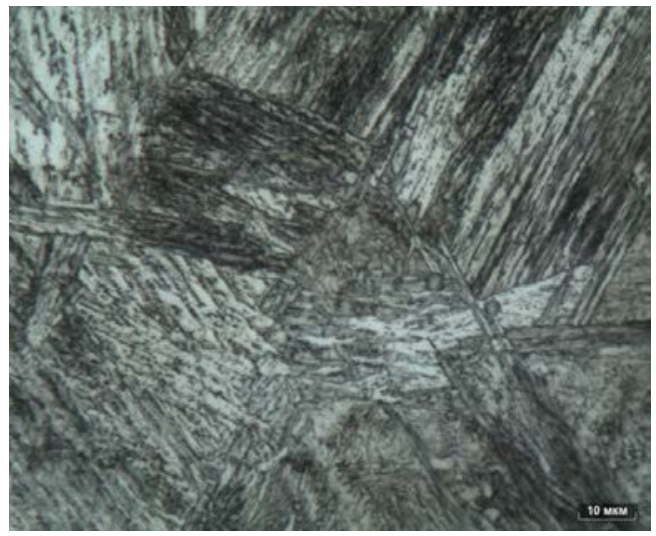

$\times 1000$

Fig. 3. The microstructure of the powder particles.

The microhardness of the particles was measured according to GOST R ISO 6507-12007 on a MicroMet 5104 microhardness meter, with a load of 100 gs, a certificate of instrument calibration dated July 26, 2017, really 12 months.

The microhardness of the powder particles is:

- sample with cond. № 1 - 294 - 382 HV0,1;

- sample with cond. № 2 - 250 - 360 HV0,1.

\section{Conclusions}

Plasma spraying allows to obtain a metal powder with a size of 5-200 microns.

The developed installation has the following advantages:

- Energy consumption is reduced by $20-30 \%$ compared to gas or water spraying, as it is not necessary to melt a large volume of metal and maintain its temperature above the melting point at $300-400{ }^{\circ} \mathrm{C}$, only a small portion of the wire melts and immediately sprayed;

- A fine powder structure is formed, for example, for LMD technology, where only the surface layer of the powder is melted and its microstructure is maintained, leads to an increase in the strength characteristics of the final products.

- A wide range of sprayed material and the production of various metal (carbon, stainless and tool steels, aluminum, copper, titanium and other metals) and ceramic (oxides, carbides and nitrides) powders on one device;

-Ability to get any amount of powder: from a few kilograms to several tons;

-Ability to control the size of the resulting powder from 5 to 200 microns, by changing the gas-dynamic and energy parameters of the plasma torch.

\section{References}

1. N.I. Urasov, About the development of the additive technologies in Russia, MODERN ECONOMICS: PROBLEMS AND SOLUTIONS, 9(69), pp 72-73 (2015).

2. E. P. Sebekova, N.I. Viterska, The development of innovative technologies in the Russian Federation, MODERN ECONOMY: PROBLEMS AND SOLUTIONS, 12 (96), pp 114-122 (2017). 
3. N. N. Strukov, Development of technology of plasma spray rod shaped material in the chamber with protivopoloznom: dissertation of candidate of technical Sciences (Perm, 2012).

4. A.R. Ibragimov, T.A. Ilinkova, L.N. Shafigullin, A.T.Gabdrakhmanov, R.R.Sharipov, A.A.Lakhno, Investigation of mechanical properties of thermal barrier coating by tested on a 4-point bending, Research Journal of Pharmaceutical, Biological and Chemical Sciences, v. 7, pp. 2308-2317 (2016).

5. V. L. Fedyaev, E. R. Galimov, A. V. Belyaev, A. V. Dolgov, V. M. Samoylov, Evaluation of interphase boundaries dynamics at the contact of melt with solid material, IOP Conf. Series: Materials Science and Engineering, v. 412 number 012015 (2018).

6. V. I. Astashchenko, N. N. Zapadnova, G. F. Mukhametzianova, A. N. Shafigullina, Key concepts for production of high-quality parts, IOP Conference Series: Materials Science and Engineering, v. 240 issue 1, number 012007 (2017).

7. E. R. Galimov, A. I. Shveyov, T. V. Shveyova, E. E. Sharafutdinova, A. V. Belyaev, L. V. Sirotkina, Method of predicting the hardness of welded joints, International Journal of Applied Engineering Research, v. 11, Number 3, pp. 1603-08 (2016).

8. A. T. Gabdrakhmanov, I. H. Israphilov, A. T. Galiakbarov, A. D. Samigullin, Improving the efficiency of plasma heat treatment of metals,/ Journal of Physics: Conference Series, v. 669, article number 012014 (2016).

9. A. T. Gabdrakhmanov, L.N. Shafigullin, E. R. Galimov, A.R. Ibragimov, Surface thermohardening by the fast-moving electric arch, IOP Conf. Series: Journal of Physics: Conf. Series, v. 789, Article number 012010 (2017). 